\title{
Consequences of lipopolysaccharide and n-3 polyunsaturated fatty acid administration on aortic function of spontaneously hypertensive rats
}

\author{
Barbara Kaprinay ${ }^{1,2}$, Ruzena Sotnikova ${ }^{1}$, Karel Frimmel ${ }^{3}$, Jakub Krizak ${ }^{3}$, Iveta Bernatova ${ }^{4}$, \\ Jana Navarova ${ }^{1}$ and Ludmila Okruhlicova ${ }^{3}$ \\ ${ }^{1}$ Institute of Experimental Pharmacology and Toxicology, Slovak Academy of Sciences, 84104 Bratislava, Slovakia \\ ${ }^{2}$ Comenius University in Martin, Jessenius Faculty of Medicine, Institute of Pharmacology, Martin, Slovakia \\ ${ }^{3}$ Institute for Heart Research, Slovak Academy of Sciences, 84005 Bratislava, Slovakia \\ ${ }^{4}$ Institute of Normal and Pathological Physiology, Slovak Academy of Sciences, 81371 Bratislava, Slovakia
}

\begin{abstract}
The aim of the work was to study the delayed effect of lipopolysaccharide (LPS) administration on endothelial function of the aorta of rats with genetic hypertension. Further, the possibility to ameliorate LPS-induced changes by $n-3$ polyunsaturated fatty acids (n-3 PUFA) was tested. Rats received a bolus of $1 \mathrm{mg} / \mathrm{kg}$ LPS i.p.; $\mathrm{n}-3$ PUFA were administered in the dose of $30 \mathrm{mg} / \mathrm{kg}$ daily for 10 days p.o.. Ten days after receiving of LPS, the body weight gain of rats was statistically lower compared to control rats $(p<0.05)$. n-3 PUFA administration to LPS rats had no effect on this parameter. The TBARS and NAGA concentrations in plasma were significantly increased in the LPS group $(p<0.05)$ and n-3 PUFA administration returned them to control values. In functional studies, phenylephrine (PE, $1 \mu \mathrm{mol} / \mathrm{l})$ evoked contraction of aortas which was not statistically different among experimental groups. However, endothelium-dependent relaxation was depressed in the LPS group $(p<0.05)$ and n-3 PUFA slightly recovered it to control values. In conclusion, oxidative stress seems to be responsible for aortic endothelial dysfunction detected 10 days after administration of LPS to rats. n-3 PUFA slightly improved the function of the endothelium injured by LPS, probably thanks to their antioxidant properties. Prolonged administration of higher doses of n-3 PUFA should defend the vascular endothelium against detrimental effect of bacterial inflammation.
\end{abstract}

Key words: Lipopolysaccharide — Omega-3 fatty acids — Spontaneously hypertensive rats - Aorta

\begin{abstract}
Abbreviations: CRP, C-reactive protein; DHA, docohexaenoic acid; eNOS, endothelial NO-synthase 2; EPA, eicosapentaenoic acid; HTG, hypertriglyceridemic; IL1 $\beta$, interleukin $1 \beta$; iNOS, inducible NO-synthase 2; LPS, lipopolysaccharide; n-3 PUFA, omega-3 polyunsaturated fatty acids; NAGA, $\mathrm{N}$-acetyl- $\beta$-D-glucosaminidase; PE, phenylephrine; PSS, physiological salt solution; SHR, spontaneously hypertensive rat; TBARS, thiobarbituric acid reactive substances; TNF- $\alpha$, tumor necrosis factor $\alpha$.
\end{abstract}

\section{Introduction}

Lipopolysaccharide (LPS) or endotoxin is the glycolipid present in the outer membrane of gram-negative bacteria. It generally consists of a hydrophobic lipid A domain,

Correspondence to: Barbara Kaprinay, Institute of Experimental Pharmacology and Toxicology, Slovak Academy of Sciences, Dubravska cesta 9, 84104 Bratislava, Slovakia

E-mail: barbara.kaprinay@savba.sk an oligosaccharide core, and the outermost $\mathrm{O}$-antigen polysaccharide (Raetz and Whitfield 2002). Lipid A is a di-glucosamine-based lipid that serves as a hydrophobic anchor of LPS to the microbial membrane and is the single region of LPS that is recognized by the innate immune system. Slightly elevated levels of LPS persist in humans with chronic diseases and lifestyles that involve chronic smoking and drinking (Morris et al. 2015).

Cellular responses to LPS depend on its dose - high doses cause acute, resolving inflammation, while lower 
doses are associated with low-grade and chronic nonresolving inflammation. Elevated circulating endotoxin may program host leukocytes into a low-grade "memory" state and contribute to the pathogenesis of diverse diseases including atherosclerosis, diabetes, Parkinson's disease, etc. (Manco et al. 2010; Mehta et al. 2010; Wiesner et al. 2010; Morris et al. 2015).

Recent evidence indicates that the endothelium does not play a passive role in systemic inflammatory states. Endothelial cells produce an abundance of inflammatory mediators and elements of the immune and coagulation systems in the host response to inflammatory stimulation. The barrier function of the endothelium is impaired by endotoxins and is likely to contribute to adverse outcomes. A number of authors have recently developed a concept of the aberrant and dysfunctional endothelial barrier as the central pathophysiological process in LPS-induced inflammation and septic shock (Schouten et al. 2008; Opal and van der Poll 2015).

Endothelial dysfunction is now well established as a pivotal early event in the development of major cardiovascular diseases including hypertension, atherosclerosis and diabetes. Pre-clinical studies have indicated that polyphenol-rich food and food-derived products, e.g. grape-derived products and omega- 3 fatty acids, can trigger pathways in endothelial cells promoting an increased formation of $\mathrm{NO}$ and endothelium-dependent hyperpolarization. Moreover, intake of such food-derived products has been associated with the prevention and/or the improvement of an established endothelial dysfunction in several experimental models of cardiovascular diseases and in humans with cardiovascular diseases (Auger et al. 2016).

The lipid A component of LPS in picomolar concentrations is sufficient to cause endothelial cell injury by promoting the expression of tissue factor and proinflammatory cytokines like tumor necrosis factor $\alpha$ (TNF- $\alpha$ ) and interleukin $1 \beta$ (IL1 $\beta$ ) (Miller et al. 2005), leading to apoptosis of endothelial cells (Bannerman et al. 2002). Different bacterial infections accompany us from birth to old age. Presumably, each inflammation might affect the function of the endothelial membrane and consequently lead to injury of vessels and organs they supply. Regular consumption of compounds with the protective membrane effects could be beneficial for normal function of vessels.

Polyunsaturated fatty acids are natural constituents of the diet, with a wide spectrum of physiological effects (Komatsu et al. 2003; Calder 2012). Their anti-inflammatory properties were documented experimentally and confirmed by clinical trials. In cultured macrophages polyunsaturated fatty acids decreased the expression of 10 genes related to inflammation (Allam-Ndoul et al. 2016). Clinical trials on fish oil in patients with rheumatoid arthritis (Kremer et al. 1985) showed a significant anti-inflammatory activity of the combination of eicosapentaenoic (EPA) and docosahexaenoic acid (DHA).
Various studies confirmed that chronic consumption of fish oil or omega-3 polyunsaturated fatty acids (n-3 PUFA) reduced atherosclerosis (Shim et al. 2016) and ameliorated heart failure (Chrysohoou et al. 2016). n-3 PUFA protect the function and integrity of the endothelium against injury, preventing structural remodeling of the vascular wall. Our previous studies showed n-3 PUFA diet-induced modulation of $\mathrm{Cx} 43$ expression in the aorta and heart of hypertriglyceridemic (HTG) and hypertensive rats (Mitasikova et al. 2008; Dlugosova et al. 2009a, 2009b), as well as modulation of endothelial Cx40 expression in the aorta of Wistar rats injected with LPS (Frimmel et al. 2014), supporting the involvement of intercellular communication in protective effects of n-3 PUFA.

In essential hypertension, in animals as well as in humans, chronic vascular and immune dysfunctions are closely associated. In spontaneously hypertensive rats (SHR), various vascular alterations have been reported, e.g. increased activity of the sympathetic system, endothelial dysfunction, arterial compliance decrease, and medial hypertrophy (Folkow 1982; Chobanian 1990). SHR also exhibit immune abnormalities with defective leukocyte-endothelial cell interactions, depressed $\mathrm{T}$ lymphocyte functions, decreased delayed-type hypersensitivity (Dzielak 1990, 1992), and chronic inflammatory process in the cardiovascular system (Hinglais et al. 1994). All these observations suggest direct interaction of the cardiovascular and immune systems in SHR. Thus, the response of the rat organism to LPS administration can be influenced by hypertension.

The aim of the work was to study the effect of LPS on endothelial function of the aorta of rats with genetic hypertension (SHR) 10 days after LPS administration. Further, the possibility to ameliorate LPS-induced changes by $n-3$ PUFA was tested.

\section{Materials and Methods}

The investigation conformed to the Guide for the Care and Use of Laboratory Animals. The experiments were approved by the State Veterinary and Food Administration of the Slovak Republic.

Experiments were done on 3-month-old male SHR (Breeding station Dobrá Voda, Slovakia), weighing 220.4 $\pm 5.4 \mathrm{~g}$. They were housed in a room with air temperature of $22-24^{\circ} \mathrm{C}, 45-60 \%$ humidity and regular light control -12 hours light and 12 hours dark. They were given standard rodent chow and water ad libitum. All procedures were done at the same time during the light phase of the L/D cycle. The acclimatization period lasted 10 days.

The rats were randomly assigned to three experimental groups (each of 8 animals): $\mathrm{C}$, control group without any treatment; LPS, rats received bolus of $1 \mathrm{mg} / \mathrm{kg}$ LPS i.p.; LPS $+n-3$ PUFA, LPS rats treated with n-3 PUFA in the dose 
of $30 \mathrm{mg} / \mathrm{kg}$ daily for 10 days p.o. by gavage. The chosen dose was based on our previous studies (Dlugosova et al. 2009b). Administration of n-3 PUFA (57\% EPA and 43\% DHA commercial nutritional supplement MaxiCor, SVUS Pharma, Czech Republic) was started on the same day as that of LPS. Treatment of healthy animals with n-3 PUFA had no effect on the parameters measured and are thus not presented in this work. LPS (Escherichia coli serotype 055:B5, Sigma Chemical, Germany) was dissolved in sterile $0.9 \% \mathrm{NaCl}$ solution. The rats from the control group were injected with the same volume of sterile $0.9 \% \mathrm{NaCl}$ solution.

The animals were weighed at the beginning and end of the experiment, systolic blood pressure was measured at the same period by non-invasive plethysmographic method on the rat tails. After 10 days of the experiment, the rats were anesthetized with thiopental (50 mg/kg i.p.) and killed by heart excision. Blood was used for evaluation of markers of oxidative stress and the thoracic aorta was removed. Markers of oxidative stress - concentrations of thiobarbituric acid reactive substances (TBARS) - were determined in plasma according to Esterbauer (1993). The plasma specific activity of lysosomal $N$-acetyl- $\beta$-D-glucosaminidase (NAGA), a marker of cellular injury, was assayed according to standard methods as described previously in Navarova and Nosalova (1994).

\section{Isolated rat aorta}

The thoracic aorta was excised and transferred into oxygenated physiological salt solution (PSS). The arteries were cleaned of adherent tissue and cut into rings, approx. 2-3 mm long. Special care was taken not to damage the endothelium. The rings were mounted between two hooks in water-jacketed $\left(37^{\circ} \mathrm{C}\right)$ chambers containing PSS bubbled with a mixture of $95 \% \mathrm{O}_{2}$ and $5 \% \mathrm{CO}_{2}$ at $\mathrm{pH}$ 7.4. The composition of PSS was (in mmol/l): $\mathrm{NaCl}(118.0), \mathrm{KCl}(4.7), \mathrm{KH}_{2} \mathrm{PO}_{4}(1.2), \mathrm{MgSO}_{4}$ (1.2), $\mathrm{CaCl}_{2}$ (2.5), $\mathrm{NaHCO}_{3}$ (25.0), and glucose (11.0). The preparations were connected to an isometric force transducer (Experimetria Hungary), stretched passively to $10 \mathrm{mN}$ and equilibrated for 60 minutes.

Experimental protocol: After the equilibration period, contraction was induced by submaximal concentration of phenylephrine (PE, $\left.10^{-6} \mathrm{~mol} / \mathrm{l}\right)$. At the plateau of the contraction, the effect of acetylcholine in the cumulative concentrations of $10^{-8}-10^{-5} \mathrm{~mol} / \mathrm{l}$ was tested as a measure of endothelial function. After washing with PSS and reaching the initial tension value, concentration-response curves of sodium nitroprusside $\left(10^{-10}-10^{-7} \mathrm{~mol} / \mathrm{l}\right)$ were performed in $\mathrm{PE}$-precontracted preparations.

\section{Statistical analysis}

Data are expressed as mean \pm SEM. The mechanical responses are expressed as percentages of the PE-induced contraction.
Statistical analysis was performed by using ANOVA with Bonferroni posttest. Statistical significance was indicated at $p<0.05$. The $\mathrm{pD}_{2}$ values (- $\log$ of concentration inducing $50 \%$ of maximal response) were calculated by Graph Pad.

\section{Results}

Ten days after a non-lethal dose of LPS (1 mg/kg b.w.), we evaluated the physiological state of the rats. As seen in Fig. 1, body weight gain of LPS rats was statistically lower compared to controls. n-3 PUFA administration to LPS rats had no effect on this paramater. Blood pressure changes were not found among the experimental groups. The final systolic blood pressure of each group did not increase significantly in comparison to starting values (Fig. 2). The TBARS concentration in plasma was significantly $(p<0.05)$ increased in the LPS group (4.06 $\pm 0.36 \mu \mathrm{g} / \mathrm{mg}$ prot.) and $\mathrm{n}-3$ PUFA administration returned it to the control values (LPS $+n-3$ PUFA: $3.49 \pm 0.18 \mu \mathrm{g} / \mathrm{mg}$ prot., C: $3.18 \pm 0.07 \mu \mathrm{g} / \mathrm{mg}$ prot.). Similarly, plasma specific NAGA activity was augmented in the LPS group (from $0.14 \pm 0.01$ to $0.18 \pm 0.02 \mu \mathrm{g} 4-\mathrm{NP} / \mathrm{min} /$ mg prot., $p<0.05)$ and ameliorated in the LPS $+n-3$ PUFA group $(0.13 \pm 0.02 \mu \mathrm{g} 4-\mathrm{NP} / \mathrm{min} / \mathrm{mg}$ prot.) (Fig. 3$)$.

The LPS dose used increases levels of C-reactive protein (CRP) which justify the presence of inflammation (Frimmel et al. 2014).

In functional studies, $\mathrm{PE}$ in the concentration of $1 \mu \mathrm{mol} / \mathrm{l}$ evoked contraction which was not statistically different among the experimental groups (not shown). In the control group, acetylcholine induced endothelium-dependent relaxation with the $\mathrm{pD}_{2}$ value of $7.78 \pm 0.11$ and the maximal relaxation of $25.61 \pm 4.78 \%$ of PE-induced contraction. However, responses of LPS aortas were attenuated $\left(\mathrm{pD}_{2}\right.$ $7.39 \pm 0.25$, maximal response $49.33 \pm 8.43 \%$ of $\mathrm{PE}$-induced

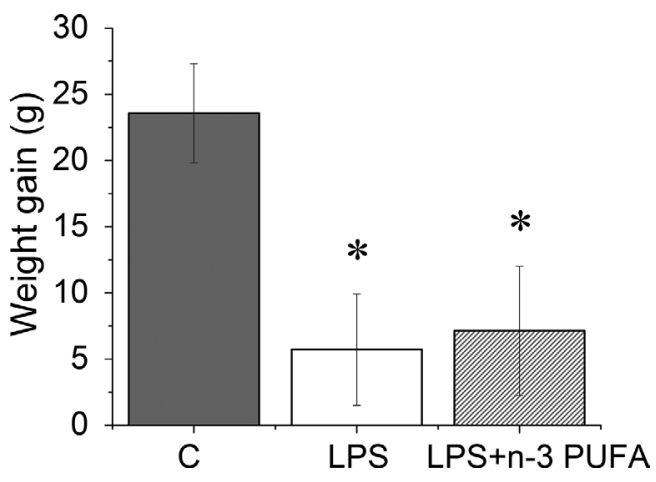

Figure 1. Body weight gain in control animals (C), animals which received LPS (LPS), and LPS animals treated with n-3 PUFA (LPS $+n-3$ PUFA). Data are means \pm SEM (standard error of the mean) from 8 animals. ${ }^{*} p<0.05 v s$. C. 


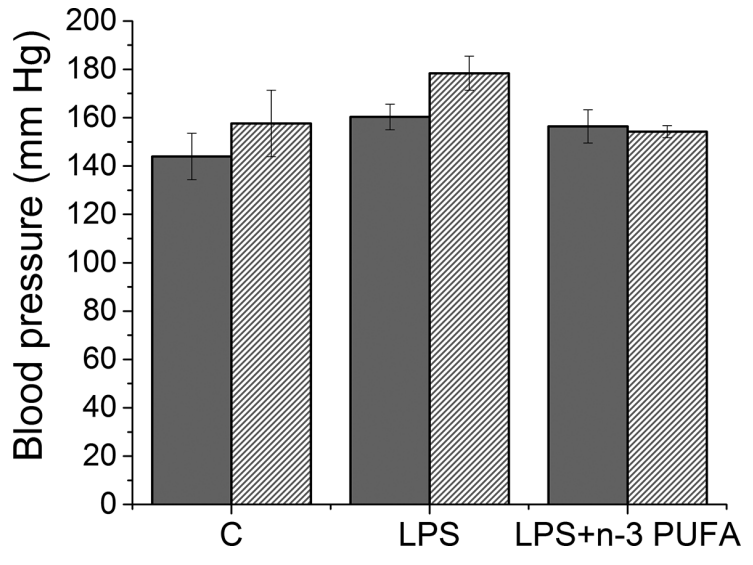

Figure 2. Systolic blood pressure at the beginning (full columns) and the end (laminated columns) of the experiment. C, control animals, LPS, animals which received LPS; LPS+n-3 PUFA, animals treated with n-3 PUFA. Data are means \pm SEM from 8 animals.

contraction). n-3 PUFA administered to LPS animals slightly shifted endothelium-dependent relaxation to that of controls $-\mathrm{pD}_{2}$ value $7.72 \pm 0.20$, maximal relaxation $41.97 \pm 7.31$ (Fig. 4). No differences between groups were found in the response to sodium nitroprusside (not shown).

\section{Discussion}

Single LPS administration caused loss of body weight in SHR rats. Likewise, reduced body weight gain was found in HTG rats using the same LPS experimental model (Frimmel et al. 2016). Our data correspond with the study of Valles et al. (2000) who demonstrated that even a single exposure to stressors, including LPS, can cause long-lasting reduced food intake and affect consequently the body weight, which is mediated by different metabolic or neural mechanisms
(Liu et al. 2016). On the other hand, we did not find changes in systolic blood pressure after LPS administration to SHR. We speculate that this might be due to dose- and routedependent application of LPS, duration of its influence, as well as higher resistance of SHR to LPS (Bernard et al. 1998).

It is known that administration of LPS or cytokines (tumor necrosis factor or interleukin-1) to animals produces a shock-like syndrome, characterized by low blood pressure and hyporeactivity to vasoconstrictor agents (Fink and Heard 1990; Bone 1991). This response is rapid and it was confirmed also in experiment by Vo et al. (2005). These authors showed in Wistar rats that acute application of LPS to precontracted aortic rings induced endotheliumdependent relaxation which reached maximum in up to 5 hours. Moreover, isolated blood vessels of Wistar rats exposed to LPS or removed from LPS-treated animals had diminished responses to vasoconstrictor agents (Joly et al. 1994; Wu et al. 1995). Effects of LPS on the vascular system, however, seem to be dose-, and time-dependent. In our experiments, we administered a nonlethal dose (bolus of $1 \mathrm{mg} / \mathrm{kg}$ i.p.) of LPS to SHR rats and observed its effect after 10 days. As expected, the results are impacted by this protocol. Contractions induced by phenylephrine were not influenced probably as a consequence of subsided acute response. The hypotensive effect induced by the toxin seems to be dependent also on the rat strain. The SHR should be more resistant to the hypotensive effect of toxins. However, controversial results were obtained with this model. While Bernard et al. (1998) found that SHR had a greater ability to resist endotoxin shock than normotensive controls, on the other hand, Yen et al. (1997) observed a shorter survival time in SHR after LPS injection in comparison with normotensive rats.

Whereas LPS-induced vascular hyporesponsiveness to constrictor agents may be due to excessive generation of NO by inducible NO-synthase2 (iNOS) (Vo et al. 2005), the mechanism underlying LPS-induced endothelial dysfunc-
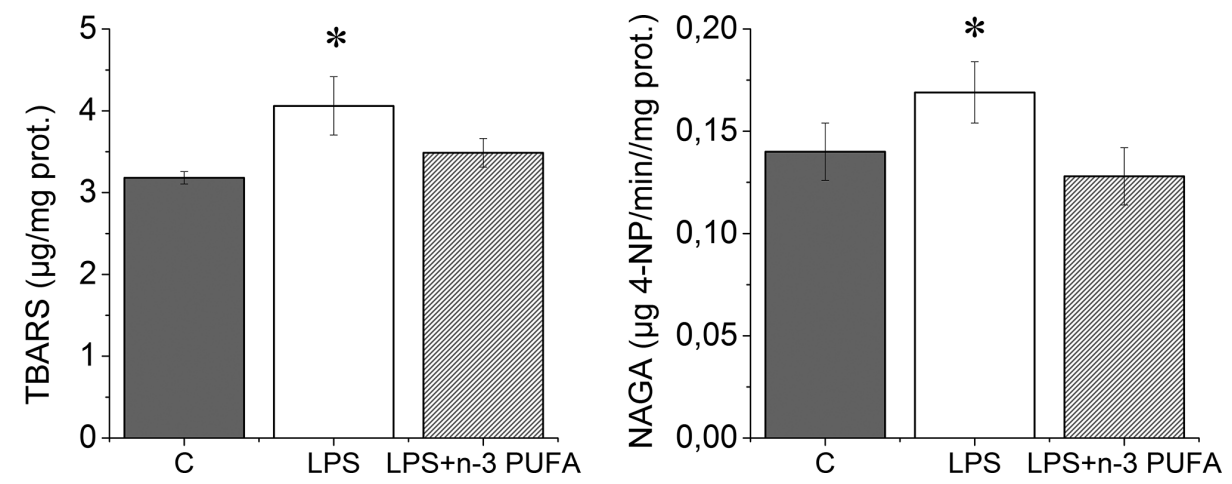

Figure 3. Plasma TBARS and specific NAGA activity (in $\mu$ g of 4-nitrophenyl NAGA) in control animals (C), animals which received LPS (LPS) and LPS animals treated with n-3 PUFA (LPS+n-3 PUFA). Data are means \pm SEM from 8 animals. ${ }^{\star} p<0.05$ vs. C. 
tion is still not clear and seems to be dependent also on animal species and vessels used. The endothelium-dependent vasodilatation of the thoracic aorta of Wistar rats was found to be significantly inhibited six hours after $10 \mathrm{mg} / \mathrm{kg}$ LPS administration (Uğurel et al. 2016). The endothelial injury was accompanied by decreased eNOS and phospho-eNOS expression. Thus changes of the ratio in eNOS/iNOS production seem to be accountable for vascular response in the acute phase of LPS administration. The most important result of our experiments is that even 10 days after LPS administration changes in endothelial function were demonstrated by reduced endothelium-dependent relaxation. At the same time, we also observed enhanced activity of the lysosomal enzyme NAGA in the LPS group compared to controls. Increased plasma and organ activity of the lysosomal enzyme NAGA indicates cell injury ongoing in the organism during pathological processes. This was found in different pathological experimental models (Nosálová et al. 2010) as well as in patients with hypertension (LisowskaMyjak et al. 2011) and with type 1 diabetes mellitus (Mandic and Filipovic 1998). Therefore, augmented NAGA activity in our study indicates cell injury remaining 10 days after LPS administration. Moreover, increased plasma levels of TBARS in animals injected with LPS suggest the presence of oxidative stress in these rats. Oxidative stress is involved in atherogenesis, which is initiated by endothelial injury in cases with cardiovascular risk factors, including diabetes mellitus, hypertension, cigarette smoking, dyslipidemia, obesity, and metabolic syndrome (Husain et al. 2015; Salmanoglu et al. 2016). Participation of oxidative stress in induction of endothelial dysfunction was confirmed by the beneficial action of antioxidants which were able to suppress the detrimental effect of reactive oxygen species (Sotníková et al. 2008, 2011). Results of Requintina and Oxengruk (2003) indicated that the effect of LPS on lipid peroxidation is dose-, time-, and species-dependent. Using the identical experimental model, we recently demonstrated in Wistar rats LPS-induced impairment of endothelium-dependent relaxation of the aorta (Frimmel et al. 2014) accompanied with increased values of NAGA activity and levels of TBARS. On the other hand, Wu et al. (1995) observed significantly impaired acetylcholine-induced relaxation in thoracic aortic rings obtained from Wistar Kyoto rats treated with LPS, but not in those from SHR. As these authors studied effects of $5 \mathrm{mg} / \mathrm{kg}$ i.v. LPS during 5 hours, we suppose that this discrepancy may be explained by different experimental protocols used.

In order to confirm endothelial damage, we studied the effect of sodium nitroprusside on the aorta to identify the effect of LPS on endothelium-independent relaxation. No differences among experimental groups were found. Our previous studies, using the same experimental LPS model, also demonstrated that LPS did not affect endothelium-

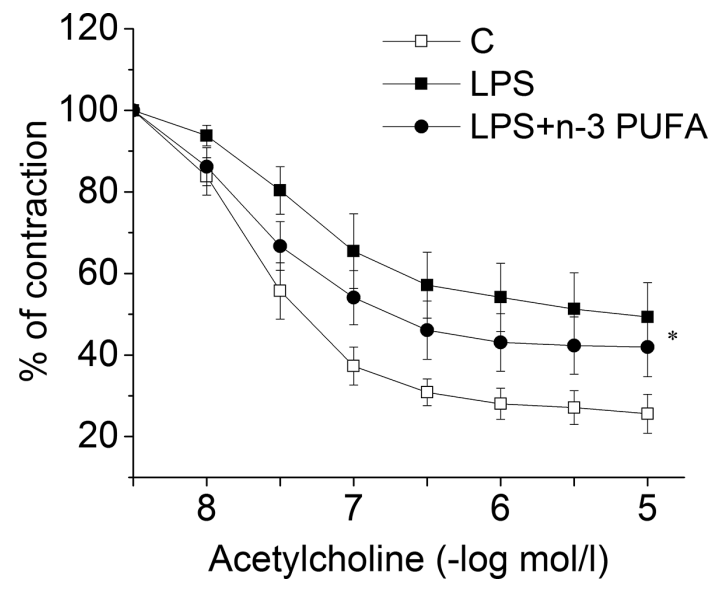

Figure 4. Endothelium-dependent relaxation of the aorta of control animals (C), animals which received LPS (LPS) and LPS animals treated with n-3 PUFA (LPS $+n-3$ PUFA). Data are means \pm SEM from 8 animals. ${ }^{\star} p<0.05$ vs. C.

independent relaxation of the aorta in Wistar and hHTG rats (Frimmel et al. 2016). The data indicate changes in endothelial function 10 days after LPS injection.

The importance of n-3 PUFA for the cardiovascular system has come under the spotlight during the last decades. Data from clinical (Colussi et al. 2016) and experimental studies (Mitasikova et al. 2008) support the hypothesis that consumption of n-3 PUFA lowers the risk of cardiovascular diseases. The n-3 index - a percentage of EPA + DHA of total fatty acids in red blood cells (von Schacky and Harris 2007) - may be a marker of increased cardiovascular risk. Our results showed that n-3 PUFA (30 mg/kg b.w.) administered for 10 days were able to suppress oxidative stress and tissue injury in the LPS group of rats. The influence of n-3 PUFA on the endothelium was not so evident, although endothelium-dependent relaxation, injured by LPS, was slightly improved. Shim et al. (2016) evoked endothelial injury in the atherosclerosis-induced erectile dysfunction rat model. They found that omega- 3 fatty acids in high doses and administered over 4 weeks were able to significantly improve intracavernosal pressure and had a beneficial role against pathophysiological consequences, such as fibrosis or hypoxic damage, in this experimental model. Further, supplementation of $4 \mathrm{~g} /$ day omega- 3 fatty acids to healthy volunteers for 4 weeks significantly decreased postprandial triglyceride elevation and postprandial endothelial dysfunction (Miyoshi et al. 2014). We thus suggest that n-3 PUFA could have a protective effect on endothelial dysfunction induced by LPS when administered over a longer time in higher doses.

In conclusion, oxidative stress seems to be responsible for aortic endothelial dysfunction detected 10 days after 
administration of LPS to rats. In the dose of $30 \mathrm{mg} / \mathrm{kg}$ daily, n-3 PUFA slightly improved the function of the endothelium injured by LPS, probably thanks to their antioxidant properties. Prolonged administration of higher doses of $n-3$ PUFA should defend the vascular endothelium against detrimental effect of bacterial inflammation.

Acknowledgements. This study was supported by VEGA grants No. 2/0065/13 and 2/0054/15. We express our thanks to M. Srnova and V. Dytrichova for their skillful technical assistance.

\section{References}

Allam-Ndoul B., Guénard F., Barbier O., Vohl M. (2016): Effect of $\mathrm{n}-3$ fatty acids on the expression of inflammatory genes in THP-1 macrophages. Lipids Health Dis. 15, 69 https://doi.org/10.1186/s12944-016-0241-4

Auger C., Said A., Nguyen P. N., Chabert P., Idris-Khodja N., Schini-Kerth V. B. (2016): Potential of food and natural products to promote endothelial and vascular health. J. Cardiovasc. Pharmacol. 68, 11-18 https://doi.org/10.1097/FJC.0000000000000382

Bannerman D. D., Erwert R. D., Winn R. K., Harlan J. M. (2002): TIRAP mediates endotoxin-induced NF-kappaB activation and apoptosis in endothelial cells. Biochem. Biophys. Res. Commun. 295, 157-162 https://doi.org/10.1016/S0006-291X(02)00638-1

Bernard C., Merval R., Esposito B., Tedgui A. (1998): Resistance to endotoxin shock in spontaneously hypertensive rats. Hypertension 31, 1350-1356 https://doi.org/10.1161/01.HYP.31.6.1350

Bone, R. C. (1991): The pathogenesis of sepsis. Ann. Inter. Med. $115,457-469$ https://doi.org/10.7326/0003-4819-115-6-457

Calder P. C. (2012): Mechanisms of action of (n-3) fatty acids. J. Nutr.142, S592-S599 https://doi.org/10.3945/jn.111.155259

Chobanian A. V. (1990): Corcoran Lecture: adaptive and maladaptive responses of the arterial wall to hypertension. Hypertension 15, 666-674 https://doi.org/10.1161/01.HYP.15.6.666

Chrysohoou C., Metallinos G., Georgiopoulos G., Mendrinos D., Papanikolaou A., Magkas N., Pitsavos C., Vyssoulis G., Stefanadis C., Tousoulis D. (2016): Short term omega-3 polyunsaturated fatty acid supplementation induces favorable changes in right ventricle function and diastolic filling pressure in patients with chronic heart failure; A randomized clinical trial. Vascul. Pharmacol.79, 43-50 https://doi.org/10.1016/j.vph.2016.01.005

Colussi G., Catena C., Novello M., Bertin N., Sechi L. A. (2016): Impact of omega-3 polyunsaturated fatty acids on vascular function and blood pressure: Relevance for cardiovascular outcomes. Nutr. Metab. Cardiovasc. Dis. 27, 191-200 https://doi.org/10.1016/j.numecd.2016.07.011

Dlugosova K., Weismann P., Bernatova I., Sotnikova R., Slezak J., Okruhlicova L. (2009a): Omega-3 fatty acids and atorvastatin affect connexin- 43 expression in the aorta of hereditary hypertriglyceridemic rats. Can. J. Physiol. Pharmacol. 87, 1074-1082 https://doi.org/10.1139/Y09-104

Dlugosova K., Okruhlicova L., Mitasikova M., Sotnikova R., Bernatova I., Weismann P., Slezak J., Tribulova N. (2009b): Modulation of connexin- 43 by omega- 3 fatty acids in the aorta of old spontaneously hypertensive rats. J. Physiol. Pharmacol. 60, 63-69

Dzielak D. J. (1990): AIDS, lupus, rheumatoid arthritis - hypertension? Hypertension 15, 95-96 https://doi.org/10.1161/01.HYP.15.1.95

Dzielak D.J. (1992): The immune system and hypertension. Hypertension 19, I36-I44 https://doi.org/10.1161/01.hyp.19.1_suppl.i36

Esterbauer H. (1993): Cytotoxicity and genotoxicity of lipidoxidation products. Am. J. Clin. Nutr. 57, 779-785

Fink, M. P., Heard, S. O. (1990): Laboratory models of sepsis and septic shock. J. Surg. Res. 49, 186-196 https://doi.org/10.1016/0022-4804(90)90260-9

Folkow B. (1982): Physiological aspects of primary hypertension. Physiol. Rev. 62, 347-504

Frimmel K., Vlkovicova J., Sotnikova R., Navarova J., Bernatova I., Okruhlicova L. (2014): The effect of omega-3 fatty acids on expression of connexin-40 in Wistar rat aorta after lipopolysaccharide administration. J. Physiol. Pharmacol. 65, 83-94

Frimmel K., Sotníková R., Navarová J., Bernátová I., Križák J., Haviarová Z., Kura B., Slezák J., Okruhlicová L. (2016): Omega-3 fatty acids reduce lipopolysaccharide-induced abnormalities in expression of connexin- 40 in aorta of hereditary hypertriglyceridemic rats. Phys. Res. 65, S65-76

Hinglais N., Heudes D., Nicoletti A., Mandet C., Laurent M., Bariety J., Michel J. B. (1994): Co-localization of myocardial fibrosis and inflammatory cells. Lab. Invest. 70, 286-294

Husain K., Hernandez W., Ansari R.A., Ferder L. (2015): Inflammation, oxidative stress and renin angiotensin system in atherosclerosis. World J. Biol. Chem. 6, 209-217 https://doi.org/10.4331/wjbc.v6.i3.209

Joly, G. A., Ayres, M., Chelly, F., Kilbourn, R. G. (1994): Effects of NG-methyl-L-arginine, NG-nitro-L-arginine, and aminoguanidine on constitutive and inducible nitric oxide synthase in rat aorta. Biochem. Biophys. Res. Commun. 199, 147-154 https://doi.org/10.1006/bbrc.1994.1207

Komatsu W., Ishihara K., Murata M., Saito H., Shinohara K. (2003): Docosahexaenoic acid suppresses nitric oxide production and inducible nitric oxide synthase expression in interferon-gamma plus lipopolysaccharide-stimulated murine macrophages by inhibiting the oxidative stress. Free Radic. Biol. Med. 34, 1006-1016 https://doi.org/10.1016/S0891-5849(03)00027-3

Kremer J. M., Bigauoette J., Michalek A. V., Timchalk M. A., Lininger L., Rynes R. I., Huyck C., Zieminski J., Bartholomew L. E. (1985): Effects of manipulation of dietary fatty acids on clinical manifestations of rheumatoid arthritis. Lancet 1, 184-187 https://doi.org/10.1016/S0140-6736(85)92024-0

Lisowska-Myjak B., Krych A., Kołodziejczyk A., Pachecka J., Gaciong Z. (2011): Urinary proteins, N-acetyl- $\beta-D-$ glucosaminidase activity and estimated glomerular filtration rate in hypertensive patients with normoalbuminuria and microalbuminuria. Nephrology 16, 403-409 
https://doi.org/10.1111/j.1440-1797.2011.01444.x

Liu Y., Huang Y., Liu T., Wu H., Cui H., Gautron L. (2016): Lipopolysaccharide rapidly and completely suppresses AgRP neuron-mediated food intake in male mice. Endocrinology 157, 2380-2392 https://doi.org/10.1210/en.2015-2081

Manco M., Putignani L., Bottazzo G. F. (2010): Gut microbiota lipopolysaccharides, and innate immunity in the pathogenesis of obesity and cardiovascular risk. Endocr. Rev. 31, 817-844 https://doi.org/10.1210/er.2009-0030

Mandic L., Filipovic D. (1998): Changes of isoensymes of serum $\mathrm{N}$-acetyl- $\beta$-glucosaminidase activity in relation to different type of diabetes. Biochem. Mol. Biol. 45, 545-554

Mehta N. N., McGillicuddy F. C., Anderson P. D., Hinkle C. C. Shah R., Pruscino L. (2010): Experimental endotoxemia induces adipose inflammation and insulin resistance in humans. Diabetes 59, 172-181 https://doi.org/10.2337/db09-0367

Miller S. I., Ernst R. K., Rader M. W. (2005): LPS, TLR4 and infectious disease diversity. Nat. Rev. Microbiol. 3, 36-46 https://doi.org/10.1038/nrmicro1068

Mitasikova M., Smidova S., Macsaliova A., Macsaliova A., Knezl V., Dlugosova K., Okruhlicova L., Weismann P., Tribulova N. (2008): Aged male and female spontaneously hypertensive rats benefit from $n-3$ polyunsaturated fatty acids supplementation. Physiol. Res. 57, 39-48

Miyoshi T., Noda Y., Ohno Y., Sugiyama H., Oe H., Nakamura K., Kohno K., Ito H. (2014): Omega-3 fatty acids improve postprandial lipemia and associated endothelial dysfunction in healthy individuals - a randomized cross-over trial. Biomed. Pharmacother. 68, 1071-1077 https://doi.org/10.1016/j.biopha.2014.10.008

Morris M.C., Gilliam E.A., Li L. (2015): Innate immune programing by endotoxin and its pathological consequences. Front. Immunol. 5, 680 https://doi.org/10.3389/fimmu.2014.00680

Navarova J., Nosalova V. (1994): Effect of H2-receptor antagonists on indomethacin-induced lysosomal enzyme release from rat gastric mucosa. Methods Find. Exp. Clin. Pharmacol. 16, 119-124

Nosálová V., Sotníková R., Drábiková K., Fialová S., Koštálová D., Banášová S., Navarová J. (2010): Chemiluminescence response induced by mesenteric ischaemia/reperfusion: effect of antioxidative compounds ex vivo. Interdisc. Toxicol. 3, 105-108 https://doi.org/10.2478/v10102-010-0021-3

Opal S. M., van der Poll T. (2015): Endothelial barrier dysfunction in septic shock. J. Intern. Med. 277, 277-293 https://doi.org/10.1111/joim.12331

Raetz C. R., Whitfield C. (2002): Lipopolysaccharide endotoxins. Annu. Rev. Biochem. 71, 635-700 https://doi.org/10.1146/annurev.biochem.71.110601.135414

Requintina P. J., Oxenkrug G. F. (2003): Differential effects of lipopolysaccharide on lipid peroxidation in F344N, SHR rats and $\mathrm{BALB} / \mathrm{c}$ mice, and protection of melatonin and NAS against its toxicity. Ann. N.Y. Acad. Sci. 993, 325-333 https://doi.org/10.1111/j.1749-6632.2003.tb07540.x

Salmanoglu D. S., Gurpinar T., Vural K., Ekerbicer N., Darıverenli E., Var A. (2016): Melatonin and L-carnitin improves endothe- lial dysfunction and oxidative stress in type 2 diabetic rats. Redox Biol. 8, 199-204 https://doi.org/10.1016/j.redox.2015.11.007

Schouten M., Wiersinga W. J., Levi M., van der Poll T. (2008): Inflammation, endothelium, and coagulation in sepsis. J. Leukoc. Biol. 83, 536-545 https://doi.org/10.1189/jlb.0607373

Shim J. S., Kim D. H., Bae J. H., Moon D. G. (2016): Effects of omega-3 fatty acids on erectile dysfunction in a rat model of atherosclerosis-induced chronic pelvic ischemia. J. Korean Med. Sci. 31, 585-589 https://doi.org/10.3346/jkms.2016.31.4.585

Sotníková R., Navarová J., Nedelčevová J., Poništ, S., Mihalová D., Kysel’ová Z., Bauerová K. (2008): Oxidative stress involvement in functional disturbances during adjuvant arthritis development in Lewis rats. Interdisc. Toxicol. 1, 112

Sotníková R., Nedelčevová J., Navarová J., Nosálová V., Drábiková K., Szöcs K., Křenek P., Kyselová Z., Bezek Š., Knezl V. et al. (2011): Protection of the vascular endothelium in experimental situations. Interdisc. Toxicol. 4, 20-26 https://doi.org/10.2478/v10102-011-0005-y

Uğurel S. S., Kuşçu N., Özenci Ç. Ç., Dalaklıŏlu S., Taşatargil A. (2016): Resveratrol prevented lipopolysaccharide-induced endothelial dysfunction in rat thoracic aorta through increased eNOS expression. Balkan Med. J. 33, 138-143 https://doi.org/10.5152/balkanmedj.2016.16879

Valles A., Marti O., Garcia A., Armario A. (2000): Single exposure to stressors causes long-lasting, stress-dependent reduction of food intake in rats. Am. J. Physiol. Regularory Integrative Comp. Physiol. 279, R1138-1144

Vo P. A., Lad B., Tomlinson J. A. P., Francis S., Ahluwalia A. (2005): Autoregulatory role of endothelium-derived nitric oxide (NO) on lipopolysaccharide-induced vascular inducible NO synthase expression and function. J. Biol. Chem. 280, 7236-7243 https://doi.org/10.1074/jbc.M411317200

von Shacky C., Harris W. S. (2007): Cardiovascular risk and the omega-3 index. J. Cardiovasc. Med. 8, S46-49 https://doi.org/10.2459/01.JCM.0000289273.87803.87

Wiesner P., Choi S.H., Almazan F., Benner C., Huang W., Diehl C. J. (2010): Low doses of lipopolysaccharide and minimal oxidized low-density lipoprotein cooperatively activate macrophages via nuclear factor kappaB and activator protein-1: possible mechanism for acceleration of atherosclerosis by subclinical endotoxemia. Circ. Res. 107, 56-65 https://doi.org/10.1161/CIRCRESAHA.110.218420

Wu C. C., Thiemermann C., Vane J. R. (1995): Glibenclamideinduced inhibition of the expression of inducible nitric oxide synthase in cultured macrophages and in the anaesthetized rat. Br. J. Pharmacol. 114, 1273-1281 https://doi.org/10.1111/j.1476-5381.1995.tb13343.x

Yen M. H., Liu Y. C., Hong H. J., Sheut J. R., Wu C. C. (1997): Role of nitric oxide in lipopolysaccharide-induced mortality from spontaneously hypertensive rats. Life Sci. 60, 1223-1230 https://doi.org/10.1016/S0024-3205(97)00066-0

Received: August 18, 2016

Final version accepted: November 4, 2016 